\title{
Study on Real Time Monitoring Method for 2-D deformation of Settlement Joint by Long Gauge FBG Sensing Technique
}

\author{
Yashuang $\operatorname{Han}^{1, a}$, Hao Zhang ${ }^{2, b^{*}}$ and Sheng shen ${ }^{3, c}$ \\ ${ }^{1}$ School of Civil Engineering, Shijiazhuang Tiedao University, Shijiazhuang 050043,China; \\ ${ }^{2}$ School of Civil Engineering, Fuzhou University; Fuzhou 350108, China \\ a15032661536@163.com, bjzrizh@126.com, 's_shen@126.com
}

Key Word: settlement joint, 2 dimensional deformations, long gauge FBG sensor, Macro strain Abstract: In this paper, to monitoring the 2-D deformation of building's settlement joint, based on the testing Macro-strain of long gauge FBG strain sensing technology, the calculating method for the 2-D deformation is derived. One kind of accurate real time monitoring method is proposed, and its reliability and accuracy are verified in Lab. Furthermore, the proposed method has been successfully applied in monitoring the settlement joint of a concrete reservoir during underneath pass construction of shield tunnel in Wuxi subway.

\section{Introduction}

In recent years, as continuously accelerated urbanization of China, the urban imprint is rapidly expanded and even extended to high altitude and beneath space, which leads to the continuously increase of urban building density day by day and the construction space squeezed smaller and smaller. Such common urban construction projects as deep foundation pit of high-storey building, subway tunnel and all types of municipal roads \& pipes are characterized by large engineering quantity, wide construction influence scope, etc. which shall have certain effect to the surrounding buildings. Therefore, in the construction for newly-built projects, the safety of adjacent buildings must be guaranteed, and the monitoring for its settlement, deformation and other index should be strengthened.

Because the rigidity of cast-in-place concrete structure is very large, its relative differential settlement is solved by placing settlement joint. As for calculation for width of settlement joint, the temporary building foundation pit code in China specifies it only relates to the number of building floors but neglect the effect from foundation inclination ${ }^{[1]}$. Based on analysis theory on interaction of neighboring foundations, Reference ${ }^{[2]}$ develops the calculation method for opposite inclination and rectifying deflection between two units of building separated by settlement joints, and applies it to the reality. However, they never mentioned the deformation and inspection problems during the operation period of settlement joint. Nowadays, the monitoring of Metro tunnels and adjacent buildings are attract more and more attentions ${ }^{[3]-[7]}$, however, the settlement joint is still monitored by manual periodic inspection, the testing error is big; furthermore testing data is not continuous and no timely alarm before accident occurrence. In current construction phase, the ground settlement caused by underneath pass construction of shield tunnel surely leads to the deformation of settlement joint of adjacent buildings, so it's an indispensible procedure to do deformation monitoring of settlement joint during the construction process. In this paper, based on Long Gauge FBG Sensing Technique, the calculation theory for 2D deformation of settlement joint is derived and verified in Lab. The corresponding real time monitoring method is proposed and applied to a water reservoir.

\section{Derivation for 2D Deformation Theory of Settlement Joint}

The settlement joint has deformation in two directions (horizontal opening and vertical dislocation), means two unknown variable. Therefore, the solution can be gained by providing two known conditions. As shown in Fig. 1, placing the Long Gauge FBG sensor I \& II in cross (the same gauge length for the sensors). The test principle of Long Gauge FBG sensor are detailed 
explained in reference[8], then the necessary know conditions can be provided. It's defined that the horizontal opening of settlement joint is "Positive" while closing is "Negative"; Anticlockwise dislocation (settlement joint on right side moves upwards) is "Positive" while clockwise dislocation (settlement joint on right side moves downwards) is "Negative". Based on the testing data of tow long guage FBG sensor, as shown in Fig.1, the horizontal opening and vertical dislocation of settlement joint can be calculated by following equation:

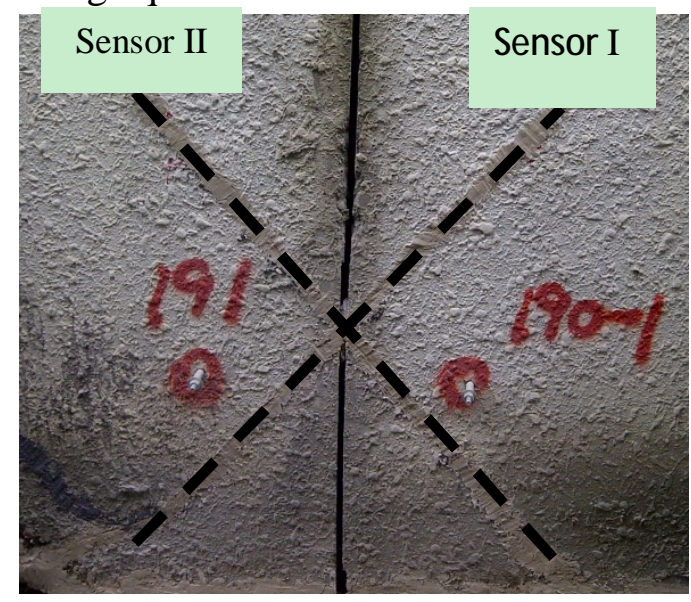

Fig. 1 Schematic diagram of sensors layout

$x=\frac{L \cdot\left(\overline{\varepsilon_{\mathrm{I}}}+\bar{\varepsilon}_{\mathrm{II}}\right)}{2 \cos \alpha}, \quad y=\frac{L \cdot\left(\bar{\varepsilon}_{\mathrm{I}}-\bar{\varepsilon}_{\mathrm{II}}\right)}{2 \sin \alpha}$

For the convenient of discussion on result, we make rules for the positive and negative value of " $x$ " and " $y$ ", in which " $x$ " value is positive as the horizontal width increase of settlement joint and negative in the other way around. Vertical dislocation is positive if left side decreased relative to right side and the negative in the other way around.

\section{Verification for Calculation Method on 2D Deformation of Settlement Joint}

To verify the abovementioned calculation principle, the simple test and verification is specially done in the Lab. please see Fig. 2 for the test device.

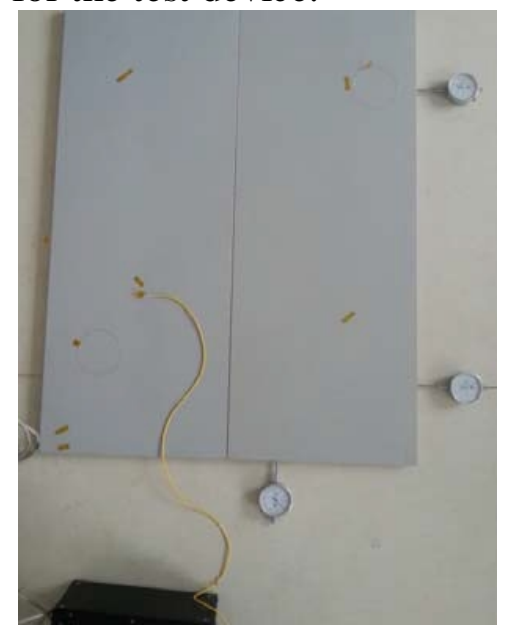

Fig. 2 Test Device in the Lab.

Sensor is pasted on two steel panels, and the steel panel is installed on sliding chute to control the deformation of steel panel. 3 dial indicators are arranged on sides of steel panel for testing the real displacement value of steel panel and comparing with calculated value from FBG sensor testing data, the gauge length of FBG sensor is $0.5 \mathrm{~m}$ and the cross angle is 45 degrees. The horizontal opening and vertical dislocation simultaneously on the experiment, the tested result is as indicated 
in Table 1. The test data presents that the derived data by proposed method is accurate and reliable, this can be used for 2D monitoring of settlement joint.

\begin{tabular}{cccccccc}
\hline step & $\begin{array}{c}\text { Sensor 1 } \\
(\mu \varepsilon)\end{array}$ & $\begin{array}{c}\text { Sensor 2 } \\
(\mu \varepsilon)\end{array}$ & $\begin{array}{c}\text { X Derived } \\
\text { value } \\
(\mathrm{mm})\end{array}$ & $\begin{array}{c}\text { X Real } \\
\text { Value } \\
(\mathrm{mm})\end{array}$ & $\begin{array}{c}\text { Y Derived } \\
\text { value } \\
(\mathrm{mm})\end{array}$ & $\begin{array}{c}\text { Y Real } \\
\text { Value } \\
(\mathrm{mm})\end{array}$ & $\begin{array}{c}\text { Max. } \\
\text { Relative } \\
\text { Error }(\%)\end{array}$ \\
\hline 1 & 141.4 & 3 & 0.05 & 0.051061 & 0.048939 & 0.05 & \\
2 & 282.8 & 1 & 0.1 & 0.100354 & 0.099646 & 0.1 & \\
3 & 424.2 & -3 & 0.15 & 0.148939 & 0.151061 & 0.15 & $-2.1 \%$ \\
4 & 565.6 & -2 & 0.2 & 0.199293 & 0.200707 & 0.2 & \\
5 & 707 & 2 & 0.25 & 0.250707 & 0.249293 & 0.25 & \\
\hline
\end{tabular}

Table 1 The testing of 2-D deformation

\section{Application in Wuxi Subway}

Project Profile

For Metro Line 2 in Wuxi City, during the section from Jinghai Park Station to Guangyi Xincheng Station, around $130 \mathrm{~m}$ passes beneath $2 \#$ water reservoir. In this passing section, the thickness from tunnel top to foundation bottom earth of water reservoir is around 8.7 9.2m, as shown in Fig. 3. Because the west wall of water reservoir is shorter and the tunnel axis of right line is close to south section of west wall, its influence by ground settlement caused by shield construction is more than that on north wall. Therefore, this paper focuses on analyzing the settlement joint of west wall.
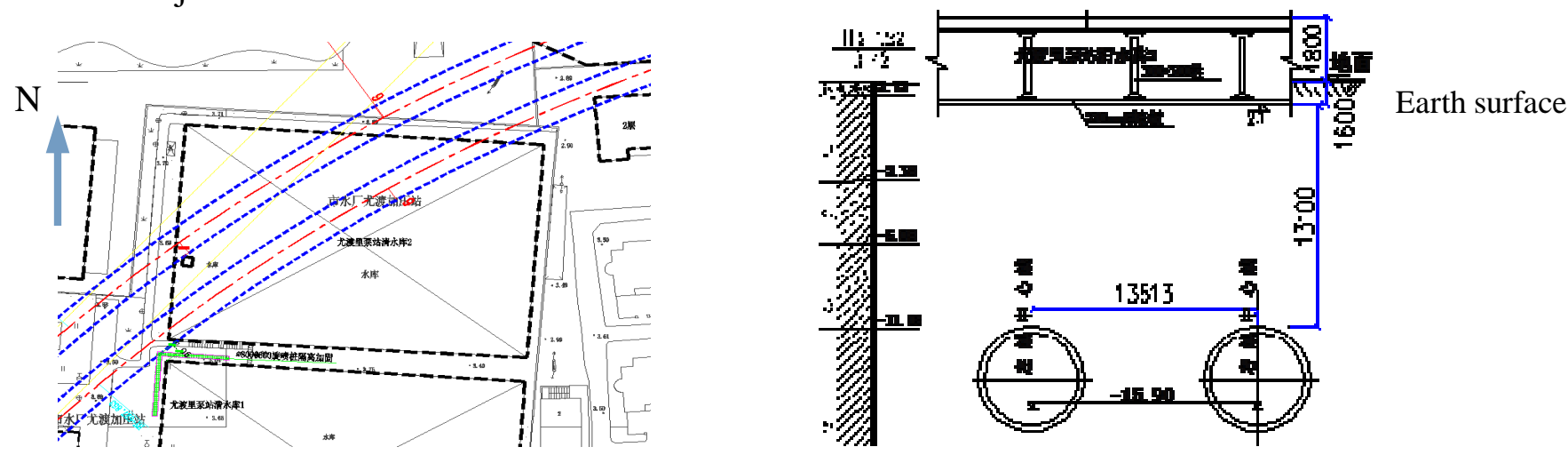

Fig. 3 Plane and vertical position relationship of tunnel and reservoir

The proposed monitoring method

The placements of sensors in settlement joint of west wall are shown in Fig. 4. The gauge length of sensor is $1 \mathrm{~m}$. Considering that opposite inclination may occur on both sides of settlement joint, 2 groups (2 sensors for each group) of sensor are placed on each settlement joint to make comparisons.

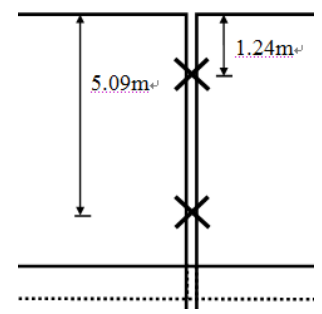

Fig. 4 Sensors layout for settlement joint in western wall 
Analysis on Monitored Data

Shield pushing influence analysis.

Fig.5 6 shows the change of horizontal opening and vertical dislocation of upper and lower parts of sensors in settlement joint during shield pushing construction period. Shield passed through north wall on Oct.6 and west wall on Oct.17, we can see that during the period when shield passed through north wall, the daily opening and closing value of settlement joint is relative smaller, and the Max. difference of opening and closing is around $0.1 \mathrm{~mm}$. During the period when shield passed through west wall, the daily opening value of settlement joint is rising but the Max. Value was not over $0.4 \mathrm{~mm}$, and the Max. Value when closing was not over $0.15 \mathrm{~mm}$. After shield passing through the west wall, the daily opening and closing value of settlement joint came back rapidly to the status before excavation.

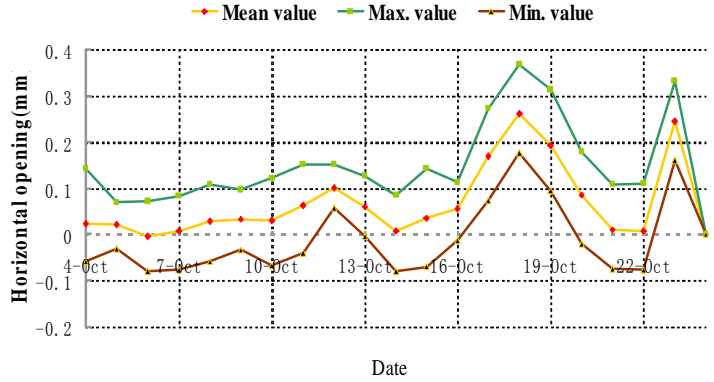

(a) Upper Side

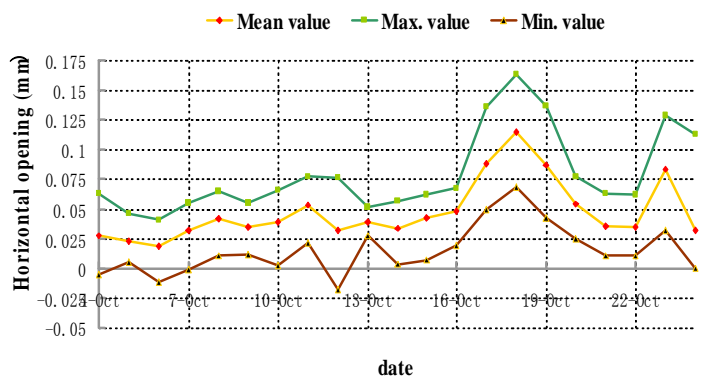

(b) Lower Side

Fig. 5 Horizontal Opening of Settlement Joint While Shield Passing Through

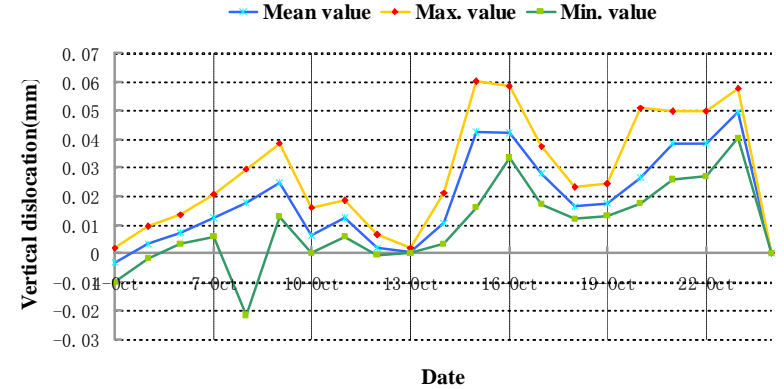

(a) Upper Side

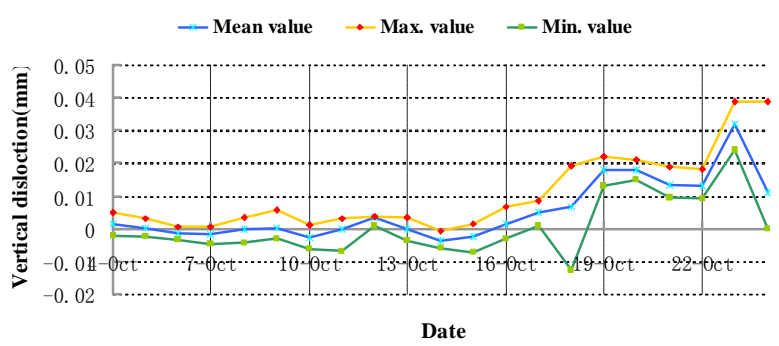

(b) Lower Side

Fig. 6 Vertical Dislocation of Settlement Joint While Shield Passing Through

Comparison monitoring data for upper and lower sensor group in settlement joint.

In construction reality, except for horizontal opening and vertical dislocation, sometimes the deformation of settlement joint also include opposite inclination. To monitor whether there's phenomenon of opposite inclination, the comparison can be made on monitored data by upper and lower sensors during the same monitoring period. There's no opposite inclination if the data keeps the same, or else, opposite inclination exists, and the corresponding measures should be taken.

The Comparison monitoring data for upper and lower sensor group in settlement joint of west wall is shown in Fig.7 $\sim 8$, the difference is the value of lower side minus the value of upper side. 


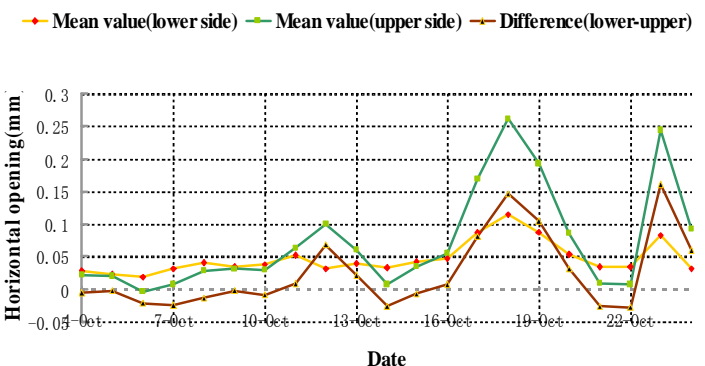

Fig. 7 Comparison on Horizontal Opening Value of Settlement Joint

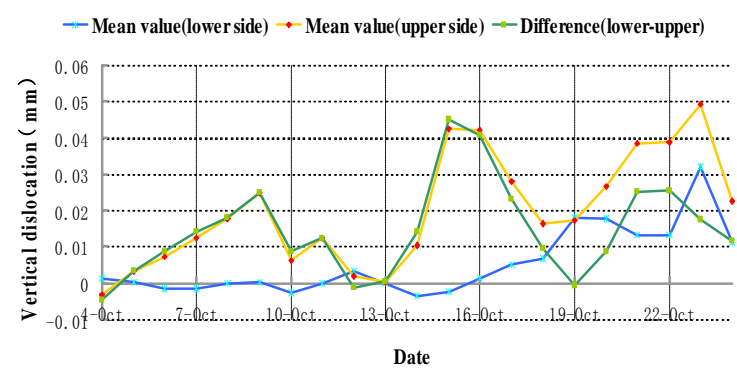

Fig. 8Comparison on Vertical Dislocation Value of Settlement Joint

According to above result, through comparing the horizontal value gained from upper and lower sensors, it is obviously that the opening value on upper side of settlement joint is slightly larger than that on lower side, namely, settlement joint presents headstand "N" shaped deformation, and the Max. difference value is $0.16 \mathrm{~mm}$, more smaller than alarm value; for vertical dislocation, the test value by upper and lower sensors has slight difference which basically could be neglected.

\section{Conclusion}

Through test \& verification in Lab. and application in real projects, it's proved that the calculating theory and monitoring solution for 2D deformation of settlement joint is feasible and reliable. Compared with traditional manual monitoring, it's characterized by high test accuracy, data continuity and other prominent characteristics, it can be promoted for use in the similar projects.

\section{Acknowledgement}

The authors would like to thank there viewers for their detailed comments that have helped to improve the quality of the paper. This work is supported by the Natural Science Foundation of Hebei Province of China (No. E2013210122); The western traffic science and technology project of China Ministry of Communications (No. 2013318780 290).

\section{Reference}

[1] (GB50001-2011), Code for Design of Building Foundation [S] Beijing: Ministry of Housing and Urban-Rural Development of the People's Republic of China, 2011.

[2] Lou Xiaoming, Li Jingpei, Pan Senfeng, Xu Renbao. Practical Cases in Opposite Inclination and Rectifying Deflection for Settlement Joint of Multi-Storey Buildings [J], Chinese Journal of Geotechnical Engineering, 2002, 04: 442-445.

[3] Lou Xiaoming, Liu Jianhang. Determination Method for Settlement Joint Width of Buildings [J]. Tongji University Journal (Nature \& Science Version), 2004, 02: 147-151.

[4] Jinfeng Zhang, Wangsheng Liu, Ming Zhao. The real time monitoring system for metro shield tunnels: from research to application, 7th European Workshop on Structural Health Monitoring,1009-1016, 2014. La Cité, Nantes, France

[5] S. Bhalla, Y.W. Yang, J. Zhao, and C. K. Soh. Structural Health Monitoring of Underground Facilities: Technological Issues and Challenges. Tunnelling and Underground Space Technology, 20:487-500, 2005.

[6] P. Wright. Assessment of London Underground Tube Tunnels-Investigation, Monitoring and Analysis. Smart Structures and Systems, 6:239-262, 2010. 
[7] Hua-Fu Pei, Jun Teng, Jian-Hua Yin, Rui Chen. A review of previous studies on the applications of optical fiber sensors in geotechnical health monitoring. Measurement, 58:207-214, 2014

[8] Li S.Z. Structural health monitoring strategy based on distributed fiber optic sensing [D]. Ibaraki University, Japan, 2007 